\title{
Analisis Penerapan Asas Kesejahteraan Hewan Pada Pemeliharaan Itik Mojosari Secara Semi-Intensif
}

\section{Analysis Of Animal Welfare Principles Application In Semi- Intensively Farming Of Mojosari Duck}

\author{
Nuruddin $^{1}$, Hananik Prasetyo ${ }^{2}$, Kartika Budi Utami $^{3}$ \\ 1,2,3 Politeknik Pembangunan Pertanian Malang; Jl. Dr. Cipto 144A Bedali Lawang \\ Malang, Telp. (0341) 427771-3 Fax. (0341) 427774 \\ ${ }^{1,2,3}$ Program Studi Penyuluhan Peternakan dan Kesejahteraan Hewan, Polbangtan \\ Malang \\ e-mail: ${ }^{1}$ nurdin.granger@gmail.com
}

\begin{abstract}
ABSTRAK
Kesejahteraan hewan di era globalisasi mulai diperhatikan banyak kalangan untuk pemenuhan konsumsi, pencegahan penyakit, dan peningkatan performa produksi. Itik Mojosari menjadi objek penelitian karena beberapa daerah di Indonesia menjadi sentra pemeliharaan secara semi-intensif. Di Kecamatan Kasembon Kabupaten Malang, itik mojosari dipelihara secara tradisional. Itik dirawat secara intensif pada umur 0-1 bulan dan digembalakan pada umur 2-5 bulan. Penelitian ini bertujuan untuk mengetahui nilai penerapan asas kesejahteraan hewan pada pemeliharaan itik mojosari. Teknik sampling secara purposive dengan kriteria pemilihan itik berumur 18 minggu. Metode analisis data secara deskriptif kuantitatif dengan mengolah data dari hasil wawancara, observasi, kuesioner, dan studi dokumentasi. Data yang didapat kemudian diolah menggunakan teknik tabulasi dengan cara merumuskan asas kesejahteraan hewan, menetapkan indikator, memberikan bobot dengan nilai 20 di setiap indikator, penentuan skala dengan interval 1-5, dan mengalikan bobot pada setiap indikator dengan skala penilaian. Kriteria penilaian asas kesejahteraan hewan berdasarkan hasil perhitungan didapatkan nilai interval 20-46 untuk farm dengan nilai kurang, angka 47-73 untuk farm dengan nilai sedang, dan 74-100 untuk penerapan dengan nilai tinggi. Dari rekapitulasi penilaian asas kesejahteraan hewan, farm di Kecamatan Kasembon telah menerapkan asas kesejahteraan hewan dengan baik dan penting untuk ditingkatkan agar memberi nilai tambah bagi kelangsungan hidup itik dan pendapatan peternak.
\end{abstract}

Kata kunci-Kesejahteraan Hewan, Itik Mojosari, Semi-intensif

\section{ABSTRACT}

Animal welfare in the era of globalization began to be considered by many people for the fulfillment of consumption, disease prevention, and increased production performance. Mojosari ducks became the object of this research because some regions in Indonesia became semi-intensively farming centers. In Kasembon Subdistrict, Malang Regency, mojosari ducks are traditionally farmed. Ducks are treated intensively at the age of 0-1 months and are shepherded at the age of 2-5 months. This study aims 
to determine the value of animal welfare principle application in mojosari ducks farming. Purposive sampling technique with 18 week old duck selection criteria. Quantitative descriptive data analysis methods by processing data from the results of interviews, observations, questionnaires, and documentation study. The data obtained is processed using tabulation techniques by formulating the principle of animal welfare, assigning indicators, assigning a value of 20 in each indicator, determining the scale at intervals of 1-5, and multiplying the value on each indicator with the rating scale. The criteria for evaluating animal welfare principles based on the calculation results are interval values of 20-46 for farms with less value, 47-73 medium value, and 74-100 for high one. From the recapitulation of animal welfare principles assessment, the farm in Kasembon subdistrict has implemented well and it is important to improve it to provide added value for duck survival and livestock income.

Keywords-Animal Welfare, Mojosari Duck, Semi-intensive

\section{PENDAHULUAN}

Tuntutan untuk memenuhi kebutuhan yang semakin baik dan berkualitas pada era milenial menjadi tantangan untuk berbagai pihak, termasuk penyedia sumber pangan. Peternakan menjadi sektor yang diperhatikan karena di era tersebut daya beli masyarakat semakin tinggi dan permintaan produk asal hewan juga meningkat. Tidak hanya itu, produk pangan asal hewan yang telah menerapkan asas kesejahteraan hewan juga lebih aman dari serangan penyakit. Sebagai contoh perusahaan makanan seperti Starbucks, Mc Donald, Burger King, dan Sodexo SA sejak tahun 2008 telah berusaha memenuhi kebutuhan produksinya dengan telur dari ayam yang terbebas dari kandang agar bisa bangkit kembali akbiat wabah flu burung di Amerika Utara (Windratie, 2015).

Kesejahteraan hewan pada era globalisasi menjadi isu yang mulai diperhatikan karena banyak aspek dalam kehidupan manusia yang berhubungan dengan hewan. Hewan sebagai makhluk hidup yang telah berperan banyak pada kehidupan manusia seperti penyedia bahan pangan, bahan industri, hewan pekerja atau hewan pemeliharaan memerlukan perhatian khusus untuk menjamin kualitas hidupnya. Kualitas hidup hewan yang baik juga akan berpengaruh nyata bagi kehidupan manusia, mulai dari tercapainya performa hewan yang optimal, nilai jual yang tinggi, hingga keramahan lingkungan yang terjaga.

Kenyataannya di negara-negara berkembang kesejahteraan hewan masih belum menjadi kewajiban untuk diterapkan pada usahanya, dan bahkan masih dianggap mengganggu kelancaran dalam melakukan pemeliharaan ternak untuk tujuan tertentu. Indonesia khususnya, masyarakat masih belum memahami makna kesejahteraan hewan secara utuh, sehingga masih sulit untuk menjamin tercapainya kesejahteraan hewan. Sebagai contoh seekor hewan yang memiliki tingkat kesejahteraan hewan yang buruk juga akan berdampak pada kemampuannya untuk produksi atau reproduksi.

Beberapa daerah di Indonesia menjadi daerah dalam melaksanakan usaha penggembalaan itik jenis mojosari fase pullet (Ismoyowati, et. al., 2013). Beternak itik mojosari menjadi pilihan dimana biaya produksi pada masa pemeliharaan bisa ditekan seminimal mungkin dengan cara 
menggembalakan itik pada daerah pasca panen padi sehingga itik dengan leluasa mampu mencari makan dan bertingkah secara alamiah di lahan persawahan. Itik mojosari masih dipelihara masyarakat dalam skala kecil dan masih tradisional, namun itik mojosari yang digembalakan mempunya peranan penting untuk menunjang perekonomian masyarakat desa.

\section{METODE PENELITIAN}

\section{Lokasi dan Waktu}

Lokasi penelitian berada di daerah pengembangan itik mojosari Kecamatan Kasembon Kabupaten Malang. Penentuan lokasi penelitian mempertimbangan itik mojosari di Kecamatan Kasembon masih memiliki potensi untuk dikembangkan terutama di Kabupaten Malang wilayah barat. Disamping itu terdapat beberapa daerah lain yang dijadikan tempat penggembalaan itik mojosari selama penggembalaan, yaitu daerah-daerah persawahan pada saat pascapanen.

Identifikasi potensi wilayah dilakukan untuk mendapatkan gambaran umum wilayah dan permasalahan yang dihadapi peternak itik. Selanjutnya penelitian di lapangan dengan mengambil data primer dan sekunder.

\section{Penentuan Populasi dan Sample Penelitian}

Populasi pada penelitian ini adalah peternak itik mojosari di Kecamatan Kasembon sejumlah 13 orang yang memiliki populasi itik 200500 ekor per orang. Teknik sampling yang digunakan yaitu purposive sampling dengan keriteria pemilihan peternak yang sedang memelihara itiknya pada usia 18 minggu. Dari hasil sampling ditentukan banyaknya sample sebagai objek penelitian sebanyak 5 orang.

\section{Sumber Data}

Data Primer

Data primer dalam penelitian diambil dari hasil wawancara dengan peternak dan meninjau langsung lokasi budidaya itik mojosari di Kecamatan Kasembon berdasarkan pada kuesioner dan kenyataan lapangan.

Data Sekunder

Data sekunder dipilih berdasarkan beberapa sumber seperti Programa Penyuluhan Kecamatan Kasembon Kabupaten Malang Tahun 2019, artikel ilmiah dan penelitian terdahulu tentang asas kesejahteraan hewan dan perhitungan pendapatan usaha.

\section{Teknik Pengumpulan Data}

Wawancara

Wawancara dilakukan untuk memperoleh informasi lebih dalam. Penelitian ini dilakukan wawancara secara langsung dengan cara mengunjungi ke rumah peternak atau ke lokasi usaha lainnya.

Observasi

Observasi dilakukan untuk mendapatkan informasi yang mendalam tentang budidaya itik mojosari secara semi-intensif dan nilai asas kesejahteraan hewan yang ada di lokasi penelitian. Indikator yang diamati berdasarkan asas kesejahteraan hewan antara lain jumlah pakan dan minum yang diberikan, model pemeliharaan, kandang, suhu, kelebaban, morfologi, serta tingkah laku itik.

Kuesioner

Kuesioner dalam penelitian ini menggunakan kuesioner tertutup dan terbuka. Kuesioner tertutup digunakan untuk mengukur nilai penerapan asas kesejahteraan hewan menggunkan skala interval, sedangkan kuesioner terbuka digunakan untuk menghitung pendapatan usaha itik mojosari. 
Kuesioner diberikan setelah melakukan wawancara kepada peternak.

Studi Dokumentasi

Dokumen digunakan untuk menganalisis kondisi lapangan secara obyektif dan komprehensif yang digunakan sebagai penjelas dari analisis deskriptif. Dokumen yang akan digali yaitu berupa foto pada pemeliharaan itik mojosari di Kecamatan Kasembon Kabupaten Malang.

\section{HASIL DAN PEMBAHASAN}

\section{Penerapan Asas Kesejahteraan Hewan}

Penilaian secara kuantitatif terhadap asas kesejahteraan hewan pada masing-masing farm terdapat pada Tabel 1.

Tabel 1. Rekapitulasi Penilaian Penerapan Asas Kesejahteraan Hewan

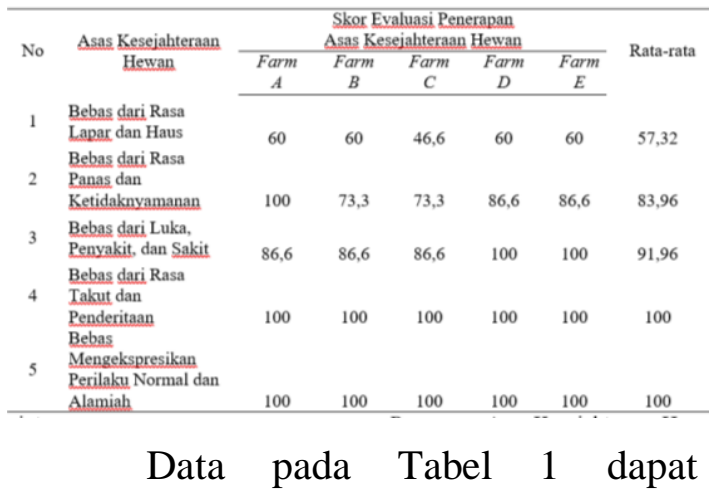
digunakan untuk mengukur tingkat kesejahteraan hewan pada farm yang diteliti. Secara umum penerapan asas kesejahteraan hewan pada budidaya itik secara semi-intensif di Kecamatan Kasembon sedang sampai tinggi. Pada asas bebas dari rasa lapar dan haus termasuk kategori sedang dengan nilai 57,32, pada asas bebas dari rasa panas dan ketidaknyamanan termasuk kategori tinggi dengan nilai 83,96, asas bebas dari luka, penyakit, dan sakit termasuk kategir tinggi dengan nilai 91,96, pada asas bebas dari rasa takut dan penderitaan serta asas bebas mengekspresikan perilaku normal dan alamiah termasuk kategori tinggi dengan masing-masing nilai 100.

\section{Asas Bebas dari Rasa Lapar dan Haus}

Berdasarkan hasil perhitungan kebutuhan pakan itik starter, maka semua farm belum mencukupi kebutuhan pakan itik yang sebesar 93 gram/ekor/hari (IP2TP, 2000).

Farm A, B, dan C memiliki nilai lebih rendah dari farm $\mathrm{D}$ dan $\mathrm{E}$ dengan dikarenakan pemberian air minum terbatas. Air minum pada farm A, B, dan $\mathrm{C}$ hanya diberikan di dalam ember dan apabila habis, banyak itik yang masih belum mendapatkan minum sehingga itik tersebut menunjukkan tanda-tanda dehidrasi. Tanda-tanda dehidrasi yang terlihat yaitu itik mengalami lemah, letih, dan murung.

Diagram nilai penerapan asas bebas dari rasa lapar dan haus terdapat pada Gambar 1.

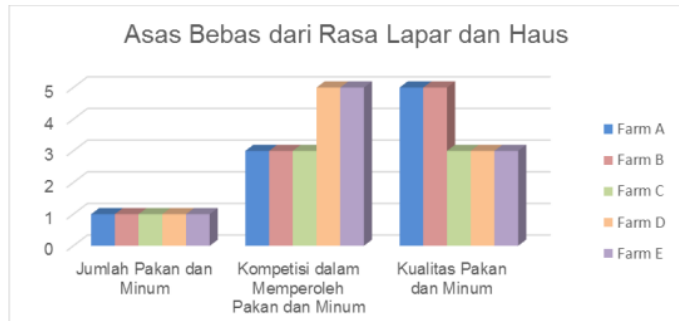

Gambar 1. Diagram Nilai Penerapan Asas Bebas dari Lapar dan Haus

\section{Bebas dari Rasa Panas dan Ketidaknyamanan}

Penerapan asas kesejahteraan hewan melalui asas terbebas dari rasa panas dan ketidaknyamanan memiliki kategori nilai sedang sampai tinggi. Farm B pada indikator durasi ternak keluar kandang memiliki nilai paling rendah daripada farm lain dikarenakan penggembalaan itik yang dilakukan terlalu singkat yaitu kurang dari 4 jam setiap harinya. 
Sedangkan pada farm lain penggembalaan yang dilakukan selama 6-8 jam perhari. Diagram penilaian penerapan asas bebas dari rasa panas dan ketidaknyamanan terdapat pada Gambar 2.

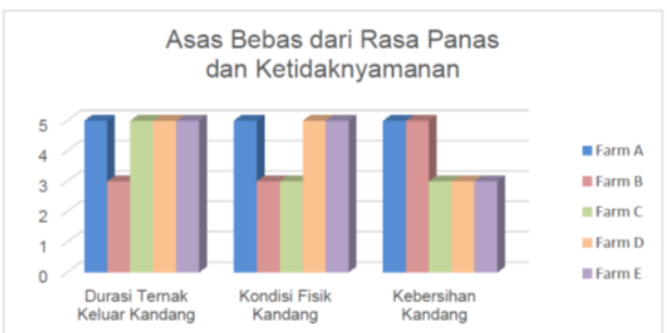

Gambar 2. Diagram Nilai Penerapan Asas Bebas dari Rasa Panas dan Ketidaknyamanan

Nilai indikator kondisi fisik kandang pada Gambar 4, farm B dan C mempunyai nilai lebih rendah dari farm lain karena jarak kandang dengan pemukiman dan jalan raya dekat sehingga ternak terganggu oleh aktifitas manusia seperti suara kebisingan. Hal tersebut sesuai dengan pendapat 52 Prayitno, dkk. (2015) bahwa kebisingan menimbulkan ketidaknyamanan lingkungan pada unggas. Kebersihan kandang pada farm C, D, dan E lebih rendah dari farm lain dengan nilai 3 karena peternak hanya membersihkan kandang terutama membuang tumpukan kotoran 1 - 2 kali dalam satu periode pemeliharaan, sedangkan pada farm lain membersihkan kandang itik sebanyak 3 - 6 kali. Kebersihan kandang yang buruk akan berpengaruh pada timbulnya penyakit, terutama penyakit pada pencernaan (Purwanti, dkk.,2016). Suhu dan kelembaban lingkungan terdapat dalam Tabel 2.

Tabel 2. Suhu dan Kelembaban Lingkungan Farm

\begin{tabular}{|c|c|c|c|c|c|c|c|}
\hline \multirow{4}{*}{ No. } & \multirow{4}{*}{ Farm } & \multicolumn{3}{|c|}{$\begin{array}{l}\text { Suhu rata-rata } \\
\left({ }^{\circ} \mathrm{C}\right)\end{array}$} & \multicolumn{3}{|c|}{$\begin{array}{l}\text { Kelembaban rata-rata } \\
(\%)\end{array}$} \\
\hline & & $\begin{array}{l}\text { Pagi } \\
(06.00\end{array}$ & $\begin{array}{l}\text { Siang } \\
(12.00\end{array}$ & $\begin{array}{l}\text { Sore } \\
(17.00\end{array}$ & $\begin{array}{l}\text { Pagi } \\
(06.00\end{array}$ & $\begin{array}{l}\text { Siang } \\
(12.00\end{array}$ & $\begin{array}{l}\text { Sore } \\
(17.00\end{array}$ \\
\hline & & $07.00)$ & $13.00)$ & $18.00)$ & $07.00)$ & $13.00)$ & $18.00)$ \\
\hline & & WIB & WIB & WIB & WIB & WIB & WIB \\
\hline 1 & Farm A & 21,85 & 29,15 & 25,6 & 84,5 & 67,5 & 70,5 \\
\hline 2 & Farm B & 21,7 & 28,8 & 25,45 & 80 & 64,5 & 70 \\
\hline 3 & Farm C & 21,85 & 28,65 & 25,15 & 80,5 & 64,5 & 67,5 \\
\hline 4 & Farm D & 21,7 & 29 & 25,85 & 82,5 & 65 & 65 \\
\hline 5 & Farm E & 21,8 & 29,15 & 25,25 & 81,5 & 65,8 & 70,5 \\
\hline
\end{tabular}

Dari Tabel 6 dijelaskan bahwa suhu dan kelembaban kandang pada setiap waktu memiliki perbedaan yang jelas. Menurut Sari, dkk. (2012) suhu kandang dan lingkungan itik yang baik yaitu pada kisaran $21-33{ }^{\circ} \mathrm{C}$, maka suhu kandang dan lingkungan pemeliharaan itik di Kecamatan Kasembon baik. Selanjutnya kelembaban kandang dan lingkungan pemeliharaan itik di Kecamatan Kasembon juga baik dengan kisaran angka $70-84,5 \%$ (Sari, dkk., 2012).

\section{Bebas dari Luka, Penyakit, dan Sakit}

Penerapan asas kesejahteraan hewan untuk menjaga ternak agar tidak terluka dan terhindar dari penyakit di semua farm yang termasuk dalam kategori sedang-tinggi. Untuk pencegahan penyakit, semua farm telah melaksanakan vaksinansi pada itik yang dipelihara. Pemenuhan vitamin untuk menunjang daya tahan tubuh juga diberikan melalui air minum. Terdapat kandang isolasi untuk itik yang sakit agar tidak terjadi penularan. Itik yang sakit diberikan perlakuan khusus dan diobati sampai sembuh. Penilaian penerapan asas bebas dari luka, penyakit, dan sakit terdapat pada Gambar 3.

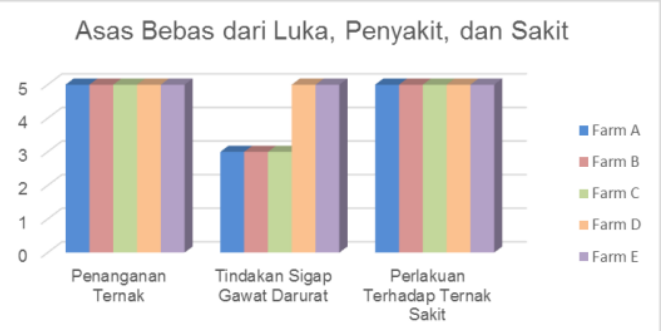

Gambar 3. Diagram Nilai Penerapan Asas Bebas dari Luka, Penyakit, dan Sakit.

Nilai pada farm A, B, dan C lebih rendah daripada farm $\mathrm{D}$ dan $\mathrm{E}$. Hal tersebut berkaitan dengan tindakan pencegahan penyakit melalui desinfeksi. Menurut Permentan No. 36 Tahun 
2007, desinfeksi yang baik adalah dengan mensucihamakan secara tepat dan cermat terhadap pakan, tempat pakan atau air minum, peralatan lain, pakaian pekerja kandang, alas kaki, kendaraan, dan bahan lain yang tercemar, bangunan kandang yang bersentuhan dengan unggas, kandang atau tempat penampungan unggas, permukaan jalan menuju kandang atau tempat penampungan unggas. Pada farm A, B, dan C tidak melakukan desinfeksi pada alas kaki dan kendaraan sebagai sarana produksi pemeliharaan itik. Fasilitas tambahan yang disediakan oleh semua farm adalah kendang isolasi dimana kandang tersebut bermanfaat untuk dijadikan kendang tempat penyembuhan itik sakit, karantina pasca sakit, atau alas an kesehatan lain sehingga manajemen rehabilitasi dalam penyembuhan penyakit itik di Kecamatan Kasembon telah dilaksanakan dengan baik.

\section{Bebas dari Rasa Takut dan Penderitaan}

Itik yang dipelihara secara semiintensif di Kecamatan Kasembon telah terhindar dari rasa takut dan penderitaan di semua farm. Tidak ada pertengkaran antar ternak dalam suatu populasi. Dalam pemeliharaan itik, peternak tidak pernah melakukan tindakan kasar seperti menendang, memukul, atau membuat itik stress pada saat penggembalaan maupun di kandang. Perlakuan kasar atau ancaman dapat meningkatkan detak jantung hewan dan berakibat hewan menjadi stress (Sofyanoor, 2012).

Penialaian asas bebas dari rasa takut dan penderittan terdapat pada Gambar 4.

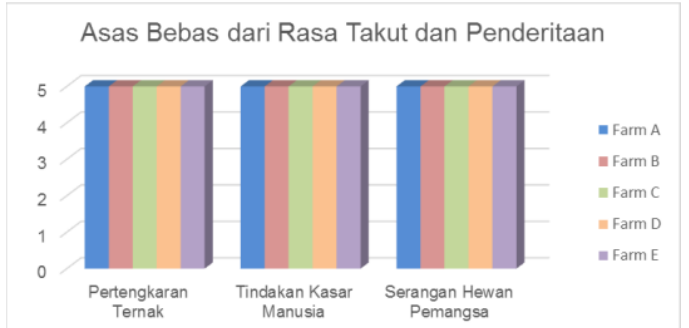

Gambar 4. Diagram Nilai Penerapan

Asas Bebas dari Rasa Takut dan Penderitaan

Morfologi atau bentuk badan dan penampakan fisik itik didapatkan hasil bahwa itik sebagian besar memiliki penampakan normal. Organ yang diamatai antara lain kepala, mata, paruh, leher, sayap, bulu, dan kaki itik.

\section{Bebas Mengekspresikan Perilaku Normal dan Alamiah}

Pemenuhan

untuk mengekspresikan perilaku normal dan alamiah itik di semua farm memiliki nilai dengan kategori tinggi. Tidak ada tindakan isolasi itik tanpa sebab yang membuat itik terpisah dari kawanannya. Luas kandang di semua farm juga cukup baik dengan kepadatan $<16$ ekor/m2, rincian luas kandang per farm terdapat pada Tabel 3 .

Tabel 3. Kepadatan Kandang

\begin{tabular}{ccccc}
\hline No. & Farm & $\begin{array}{c}\text { Populasi } \\
\text { (ekor) }\end{array}$ & $\begin{array}{c}\text { Luas } \\
\text { Kandang } \\
\left(\mathrm{m}^{2}\right)\end{array}$ & $\begin{array}{c}\text { Kepadatan } \\
\text { ekor/m }\end{array}$ \\
\hline 1 & Farm A & 500 & 50 & 10 \\
2 & Farm B & 250 & 27 & 9 \\
3 & Farm C & 350 & 24 & 15 \\
4 & Farm D & 400 & 32 & 12 \\
5 & Farm E & 350 & 24 & 15 \\
\hline
\end{tabular}

Terdapat juga kolam pemandian sehingga itik dapat mandi dan minum seperti perilaku alamiahnya. Peternak itik juga menyediakan hewan sejenis pada kawanan dengan menempatkan satu ekor itik jantan per 100 itik betina sehingga perilaku alamiah untuk kawin dapat terpenuhi. Perilaku tersebut sesuai dengan pendapat Prayitno, dkk. (2015) tentang perilaku dalam menjalankan aktifitas unggas secara rutin seperti 
perilaku makan, minum, tidur, kawin, dan kecenderungan untuk berkelompok. Penilaian penerapan asas bebas mengekspresikan perilaku normal dan alamiah itik terdapat pada Gambar 5.

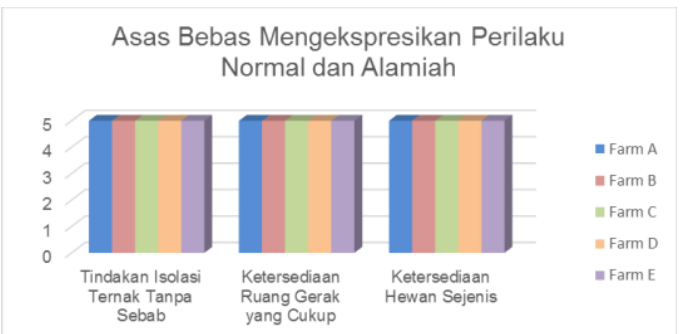

Gambar 5. Diagram Nilai Penerapan Asas Bebas Mengekspresikan Perilaku Normal dan Alamiah.

\section{Data tentang perkandangan menjelaskan bahwa semua farm mempunyai luas kandang yang sesuai dengan kepadatan populasi itik $<16$ ekor/m2 (Daud, dkk., 2017). Menurut Ali (2009) dalam Pinky, dkk.(2013), kepadatan kandang yang berlebihan dapat menurunkan pertambahan bobot badan harian.}

\section{KESIMPULAN}

Peternak itik di Kecamatan Kasembon telah melakukan usaha pemeliharaan itik mojosari berdasarkan penerapan asas kesejahteraan hewan dengan rincian ;

a. Rata-rata tingkat penerapan asas bebas dari rasa lapar dan haus mempunyai kategori sedang dengan nilai 57,32

b. Rata-rata tingkat penerapan asas bebas dari rasa panas dan ketidaknyamanan mempunyai kategori tinggi dengan nilai 83,96

c. Rata-rata tingkat penerapan asas bebas dari luka, penyakit, dan sakit mempunyai kategori tinggi dengan nilai 91,96

d. Rata-rata tingkat penerapan asas bebas dari rasa takut dan penderitaan mempunyai kategori tinggi dengan nilai 100

e. Rata-rata tingkat penerapan asas bebas mengekspresikan perilaku normal dan alamiah mempunyai kategori tinggi dengan nilai 100 .

\section{SARAN}

Diharapkan adanya penelitian eksperimental yang mengkaji tentang pengaruh penerapan asas kesejahteraan hewan terhadap performa itik mojosari serta peternak agar memperbaiki manajemen pemeliharaan itik terutama pada pemberian pakan dan minum

\section{DAFTAR PUSTAKA}

Ali, A. 2009. Performans Itik Pedaging (Lokal X Peking) FaseStarter pada Tingkat Kepadatan Kandang yang Berbeda di Desa Laboi Jaya Kabupaten Kampar. Skripsi. Fakultas Pertanian dan Peternakan Universitas Islam Negeri Sultan Syarif Kasim Riau. Riau.

Daud, M. Fuadi, Z., Mulyadi. 2017. Performan dan Persentase Karkas Ayam Ras Petelur Jantan pada Kepadatan Kandang yang Berbeda. Jurnal Agripet. ISSN : 1411-4623. Vol. 17 No. 1. Halaman 67-74.

IP2TP. 2000. Penyusunan Ransum untuk Itik Petelur. Instalasi Penelitian dan Pengkajian Teknologi Pertanian. Badan Penelitian dan Pengembangan Teknologi Pertanian. Jakarta.

Ismoyowati dan Purwantini, D. 2013. Produksi dan Kualitas Telur Itik Lokal di Daerah Sentra 
Peternakan Itik. Jurnal

Pembangunan Pedesaan. Vol. 13

No. 1. Halaman 11-16.

Kementerian Pertanian. 2007. Peraturan

Menteri Pertanian No.36 Tahun 2007 tentang Pedoman Budidaya Itik Pedaging yang Baik.

Pinky, R. P., Sujarwo, E., Achmanu. 2013. Pengaruh Kepadatan Kandang terhadap Performan Itik Hibrida dan Itik Mojosari Periode Starter. Malang : Universitas Brawijaya.

Prayitno, D. S., dan Sugiharto. 2015. Kesejahteraan dan Metode Penelitian Tingkah Laku Unggas. Semarang : Badan Penerbit Universitas Diponegoro.

Purwanti, E., Selviana., Arfan, I.. 2016. Hubungan Sanitasi Kandang, Jarak Kandang, Kepadatan Lalat, Jarak Sumber Air Bersih, dan Personal Hygiene dengan Kejadian Diare (Studi Pada Peternak Ayam di Kecamatan Benua Kayong Kabupaten Ketapang). Fakultas Ilmu Kesehatan Universitas Muhammadiyah Pontianak.

Sari O, Priyono B, Utami RN. 2012. Suhu, Kelembaban, serta Produksi Telur Itik pada Kandang Tipe Litter dan Slat. Semarang : Unnes Journal of Life Science.

Sofyanoor, M. 2012. Membumikan Animal Welfare di Indonesia. Ebuletin Veterinae Edisi ke-5. Center for Indonesian Veterinary Analytical Studies. http://civas.net/category/e-buletinveterinae/. [Diakses pada 1 Agustus 2019]. 